\title{
ANALISIS PELURUHAN GEMPA BUMI MENGGUNAKAN METODE OMORI,MOGI-UTSU I DAN MOGI-UTSU II (STUDI KASUS GEMPA BUMI BANTEN 23 JANUARI 2018)
}

\author{
Kekey Salsabil A. ${ }^{\text {a) }}$, Rika A. Ginting ${ }^{\text {b) }}$, Qadri A. ${ }^{\text {() }}$, Mohammad Kamal A. ${ }^{\text {d) }}$ \\ ${ }^{1}$ Prodi Geofisika, Sekolah Tinggi Meteorologi Kimatologi dan Geofisika \\ Jalan Perhubungan 1 no 5.Pondok Betung, Pondok Aren, Kota Tangerang Selatan, Banten 15221
}
Email : ${ }^{\text {a) }}$ kikensabila@gmail.com, ${ }^{\text {b) }}$ rikaadelinaginting@gmail.com ${ }_{2}^{\text {c) }}$ qadri.aulia15@gmail.com, d)kamal.ardiyanto@gmail.com

\begin{abstract}
Abstrak
Gempa bumi yang dijadikan studi kasus peluruhan gempa dalam tulisan ini adalah gempa bumi Banten, 23 Januari 2018. Untuk menghitung waktu berakhirnya aftershock digunakan rumus empiris dari 3 metode yaitu Metode Omori, Metode Mogi-Utsu I dan Metode Mogi-Utsu II. Data historis gempa bumi diperoleh dari BMKG (Badan Meteorologi Klimatologi dan Geofisika). Data yang digunakan berjumlah 89 data selama 22 hari. Wilayah penelitian berada pada $6.26-8.7{ }^{\circ} \mathrm{LS}$ dan $105.17-108.68{ }^{\circ} \mathrm{BT}$. Dari hasil perhitungan menggunakan 3 metode didapatkan koefisien korelasi yang berhubungan dengan berakhirnya gempa susulan. Metode yang paling tepat untuk mengetahui waktu berakhirnya gempa bumi Banten adalah Metode Omori yaitu gempa akan berakhir pada hari ke-16 untuk $\mathrm{n}(\mathrm{t})=1$ dengan koefisien korelasinya adalah 0.087 .
\end{abstract}

Kata-kata kunci: peluruhan, aftershock, Omori, Mogi-Utsu.

\begin{abstract}
The earthquake that used as a case study of earthquake decay in this paper is Banten earthquake, January 23, 2018. Empirical formulas from 3 methods are used to calculate the end of aftershock, namely Omori Method, Mogi-Utsu I Method and Mogi-Utsu II Method. Historical data on earthquakes is obtained from BMKG (Meteorology Climatology and Geophysics Agency). The data used amounted to 89 data for 22 days. The study area is at $6.26-8.77$ OLS and $105.17-108.68$ 0BT. From the results of calculations using 3 methods, the correlation coefficient is associated with the end of aftershocks. The most appropriate method to find out the time of the end of the Banten earthquake is the Omori Method, namely, the earthquake will end on the sixteenth day for $n(t)=1$ with the correlation coefficient is 0.087 .
\end{abstract}

Keywords: decay, aftershock, Omori, Mogi-Utsu. 


\section{PENDAHULUAN}

Indonesia merupakan salah satu negara yang sering mengalami peristiwa gempa bumi. Selain dikarenakan terletak pada zona ring of fire atau cincin api, Indonesia juga merupakan wilayah pertemuan tiga lempeng tektonik utama yaitu lempeng Eurasia, lempeng Indo-Australia dan lempeng Pasifik. Lempeng Indo-Australia bergerak ke arah utara mendesak lempeng Eurasia yang relatif diam dengan kecepatan $5.5 \mathrm{~cm} /$ tahun di Sumatera dan $6.9 \mathrm{~cm} / \operatorname{tahun}$ di Selatan Jawa. Kegempaan bagian timur Indonesia dikontrol oleh lempeng Pasifik yang bergerak ke arah barat mendesak lempeng IndoAustralia dengan kecepatan $10.7 \mathrm{~cm} /$ tahun.

Gempa bumi adalah peristiwa bergetarnya permukaan bumi akibat pelepasan energi secara tiba-tiba pada bagian zona lemah batuan. Energi yang dilepaskan akan menyebar ke segala arah sebagai gelombang seismik. Gelombang seismik terbagi menjadi dua, yaitu gelombang tubuh dan gelombang permukaan. Gelombang tubuh terbagi lagi menjadi dua yaitu gelombang P (primer) dan S (sekunder) sedangkan gelombang permukaan juga terbagi menjadi dua yaitu gelombang Rayleigh dan Love. Gelombang seismik yang sampai ke permukaan inilah penyebab kerusakan di permukaan bumi.

\section{TINJAUAN PUSTAKA}

Tumbukan lempeng mengakibatkan batuan mendapatkan tekanan atau stress secara terus-menerus. Ketika tekanan sudah melebihi titik elastisitas batuan, maka batuan akan pecah dan terjadilah gempa. Besar energi yang dilepaskan sama dengan akumulasi tekanan di batuan dasar, hal ini sesuai dengan konsep fisika dasar tentang Hukum Newton III yaitu Faksi = -Freaksi. Gempa bumi yang besar umumnya disebabkan oleh pemecahan batuan di dalam bumi yang segera diikuti oleh usaha pengembalian ke kedudukan setimbang (Teori Pantulan Elastis; H.F. Reid, 1911). Proses pengembalian ini yang menyebabkan terjadinya gempa bumi susulan atau aftershocks yang terjadi secara bertahap. Penentuan berakhirnya gempa bumi susulan dapat diperkirakan dengan peluruhan gempa bumi menggunakan metode Omori, Mogi Utsu I dan Mogi Utsu II.

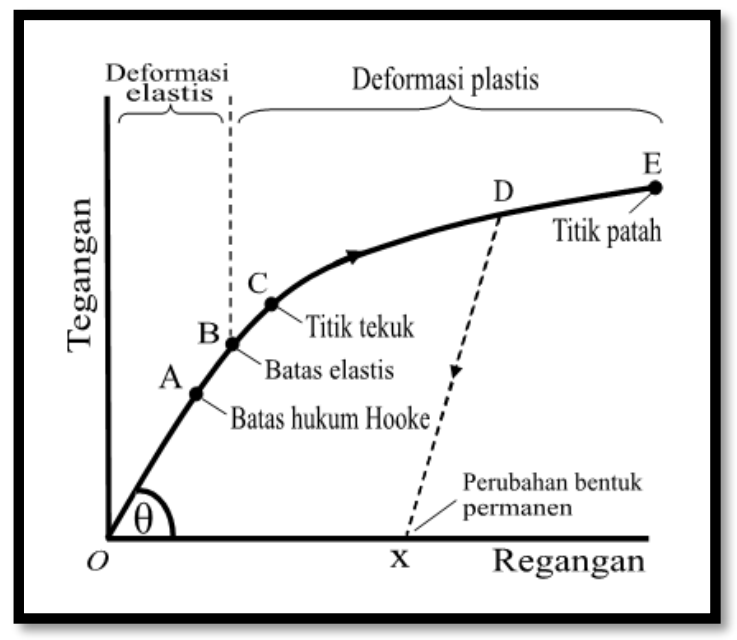

GAMBAR 1.Diagram elastisitas batuan

Mogi (1967) membagi gempa bumi menjadi tiga tipe berdasarkan urutan waktu terjadinya gempa yaitu :

a. Gempa bumi tipe I

Yakni gempa bumi utama diikuti oleh aktivitas gempa bumi susulan yang menurun terhadap waktu tanpa didahului gempa bumi pendahuluan (Mainshock - Aftershock). Tipe ini terjadi pada daerah pusat gempa dengan struktur batuan yang homogen dan tegangan yang tersebar merata. 
b. Gempa bumi tipe II

Yakni gempa bumi utama (Mainshock) diawali aktivitas gempa bumi pendahuluan (Foreshock) dan diikuti oleh gempa bumi susulan (Aftershock). Tipe ini terjadi pada daerah pusat gempa dengan struktur batuan yang tidak homogen dan distribusi tegangan yang tidak merata.

c. Gempa bumi tipe III

Yakni gempa bumi yang tidak memiliki gempa utama dengan waktu terjadinya gempa yang terus menerus atau berkepanjangan. Gempa ini disebut sebagai gempa swarm yang terjadi pada pusat gempa bumi dengan struktur batuan yang sangat tidak homogen. Penyebab utama gempa swarm adalah aktivitas magma disekitar gunung berapi.
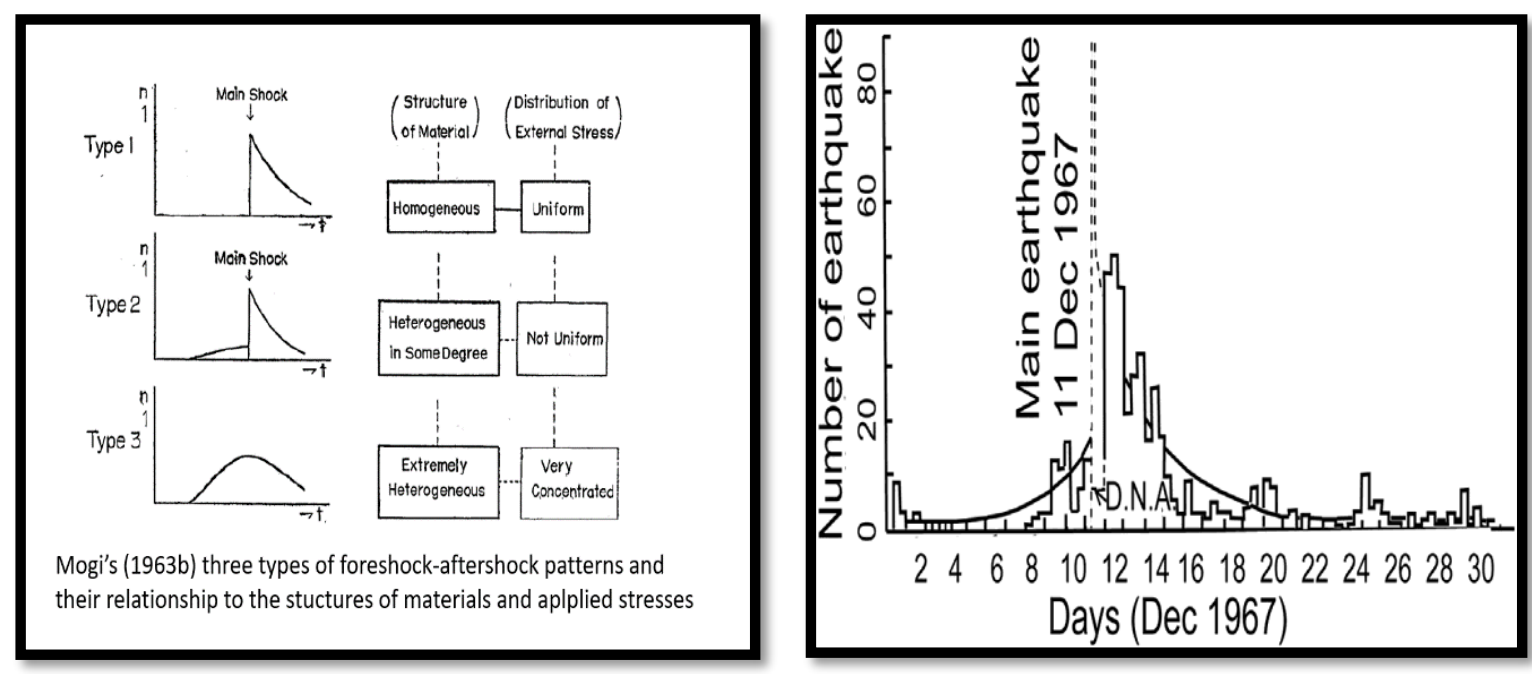

GAMBAR 2.Hubungan homogenitas dengan tipe getaran menurut Mogi (1967)

\section{Metode Omori (1894)}

Menurut Omori (1894) tingkat aktivitas gempa bumi susulan dalam hubungan antara frekuensi gempa susulan $\mathrm{n}(\mathrm{t})$ terhadap waktu $\mathrm{t}$ adalah :

$$
n(t)=\frac{a}{t+b}
$$

Untuk mendapatkan nilai koefisien a dan b digunakan regresi linier dengan banyak data $\mathrm{N}$ dan $y=$ $\frac{1}{n(t)}$ sehingga didapatkan rumus-rumus sebagai berikut :

$$
\begin{array}{cr}
\frac{1}{a}=\frac{N \Sigma(t \cdot y)-(\Sigma t)(\Sigma y)}{N \Sigma t^{2}-(\Sigma t)^{2}} & \frac{b}{a}=\frac{1}{N}\left(\Sigma y-\frac{1}{a} \Sigma t\right) \\
\rho=\frac{1}{a} \sqrt{\frac{\Sigma t^{2}-(\Sigma t)^{2}}{\Sigma y^{2}-\frac{(\Sigma y)^{2}}{N}}} & \rho=\text { koefisien korelasi }
\end{array}
$$

\section{Metode Mogi (1962) dan Utsu (1957) I}

Menurut Mogi (1962) dan Utsu (1957) I tingkat aktivitas gempa bumi susulan (untuk t $>100$ hari) dalam hubungan antara frekuensi gempa susulan $n(t)$ terhadap waktu $t$ adalah 


$$
n(t)=a \cdot e^{b t}
$$

Untuk mendapatkan nilai koefisien a dan b digunakan regresi linier dengan banyak data $\mathrm{N}$ dan $y=$ $\ln n(t)$ sehingga didapatkan rumus-rumus sebagai berikut :

$$
\begin{array}{rlr}
\ln a & =\frac{1}{N}(\Sigma y-b \Sigma t) & b=\frac{N \Sigma(t \cdot y)-(\Sigma t)(\Sigma y)}{N \Sigma t^{2}-(\Sigma t)^{2}} \\
\rho & =b \sqrt{\frac{\Sigma t^{2}-\frac{(\Sigma t)^{2}}{N}}{\Sigma y^{2}-\frac{(\Sigma y)^{2}}{N}}} & \rho=\text { koefisien korelasi }
\end{array}
$$

\section{Metode Mogi (1962) dan Utsu (1957) II}

Menurut Mogi (1962) dan Utsu (1957) II tingkat aktivitas gempa bumi susulan (untuk $\mathrm{t} \leq 100$ hari) dalam hubungan antara frekuensi gempa susulan $\mathrm{n}(\mathrm{t})$ terhadap waktu t adalah:

$$
n(t)=a \cdot t^{-b}
$$

Untuk mendapatkan nilai koefisien a dan b digunakan regresi linier dengan banyak data $\mathrm{N}$ dan nilai $x=\ln t$ dan $y=\ln n(t)$ sehingga didapatkan rumus-rumus sebagai berikut :

$$
\begin{array}{rlr}
\ln a & =\frac{1}{N}(\Sigma y-b \Sigma x) & b=\frac{N \Sigma(x \cdot y)-(\Sigma x)(\Sigma y)}{N \Sigma x^{2}-(\Sigma x)^{2}} \\
\rho & =b \sqrt{\frac{\Sigma x^{2}-\frac{(\Sigma x)^{2}}{N}}{\Sigma y^{2}-\frac{\Sigma y)^{2}}{N}}} & \rho=\text { koefisien korelasi }
\end{array}
$$

\section{METODE PENELITIAN}

Tujuan penelitian adalah untuk mengetahui metode yang tepat dalam memperkirakan waktu berakhirnya gempa bumi susulan pada kasus gempa bumi Banten 23 Januari 2018.

\section{Alat dan bahan}

1. Data gempa yang didapatkan melalui webdc3 at BMKG dengan kriteria sebagai berikut :

a. Magnitudo $\leq 6.1 \mathrm{Mw}$

b. Kedalaman $\neq 0 \mathrm{~km}$

c. Lokasi berada pada $6.26-8.77^{\circ} \mathrm{LS}$ dan $105.17-108.68{ }^{\circ} \mathrm{BT}$

d. $\quad$ Rentang waktu data antara 23 Januari 2018 sampai dengan 13 Februari 2018

2. Perhitungan dan pengolahan dilakukan dengan Microsoft Excel 2010

3. Pemetaan data gempa dilakukan menggunakan software Arcgis 10.3 
Tampilan webdc3 at BMKG yang digunakan untuk mengunduh data gempa di sekitar Banten disajikan oleh GAMBAR 3.

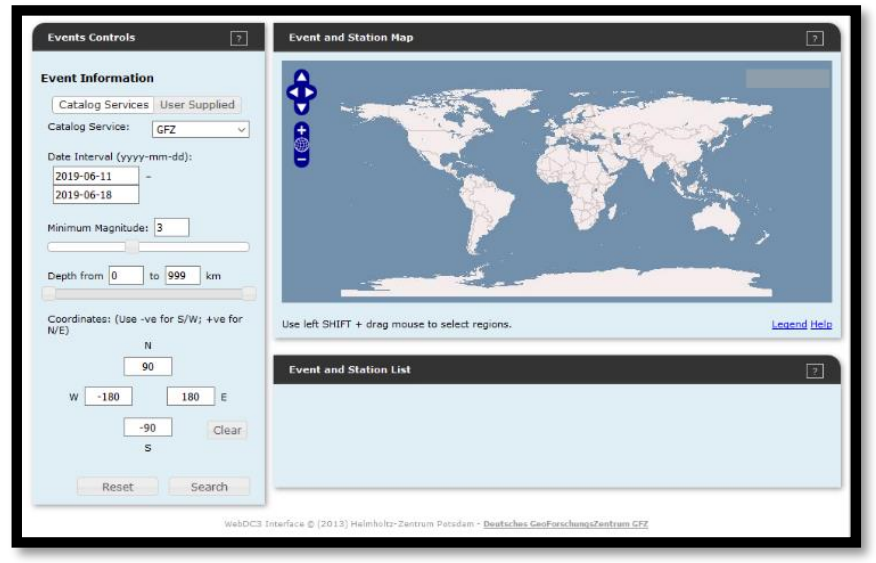

GAMBAR 3.Tampilan laman webde3 at BMKG

\section{Prosedur}

Langkah awal sebelum melakukan perhitungan dan pengolahan yaitu mengunduh data dari webdc3 at BMKG dengan kriteria yang telah ditentukan kemudian dilanjutkan dengan prosedur dibawah ini:

1. Menghitung gempa kumulatif yang terjadi

2. Menghitung nilai koefisien a dan $b$ serta nilai koefisien korelasi

3. Menentukan waktu peluruhan gempa bumi berdasarkan nilai koefisien a dan $b$ dari masingmasing metode untuk selanjutnya ditentukan yang paling tepat

4. Membuat grafik frekuensi gempa terhadap waktu

5. Membuat grafik perbandingan peluruhan gempa bumi dari ketiga metode terhadap gempa sebenarnya

6. Membuat plot peta data gempa yang didapatkan dari webdc3 at BMKG

\section{HASIL DAN PEMBAHASAN}

Berdasarkan data gempa yang di plot ke dalam perangkat lunak Arcgis 10.3 diperoleh bahwa gempa susulan tersebar di sekitar episenter gempa utama. Gempa susulan memiliki magnitudo yang lebih rendah daripada gempa induk. Simbol bintang berwarna biru menggambarkan gempa utama Banten 23 Januari 2018, lingkaran berwarna merah menggambarkan aftershock dan lingkaran berwarna kuning menggambarkan gempa lainnya.

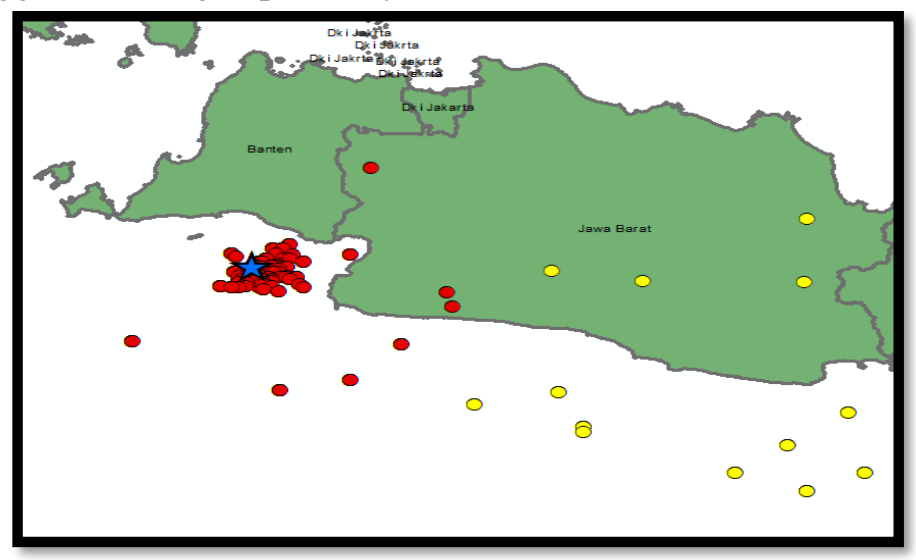

GAMBAR 4. Plot sebaran episenter gempa bumi 
Menurut perhitungan statistik peluruhan gempa bumi Banten 23 Januari 2018 didapatkan bahwa ketiga metode memberikan hasil yang berbeda-beda.Waktu berakhirnya gempa susulan bervariasi. Gempa susulan yang terjadi menurun terhadap ruang dan waktu, hal ini diakibatkan batuan yang pecah segera menemukan titik keseimbangannya. Distribusi gempa bumi selama 22 hari terhitung dari tanggal 23 Januari 2018 sampai dengan 13 Februari 2018 adalah sebagai berikut :

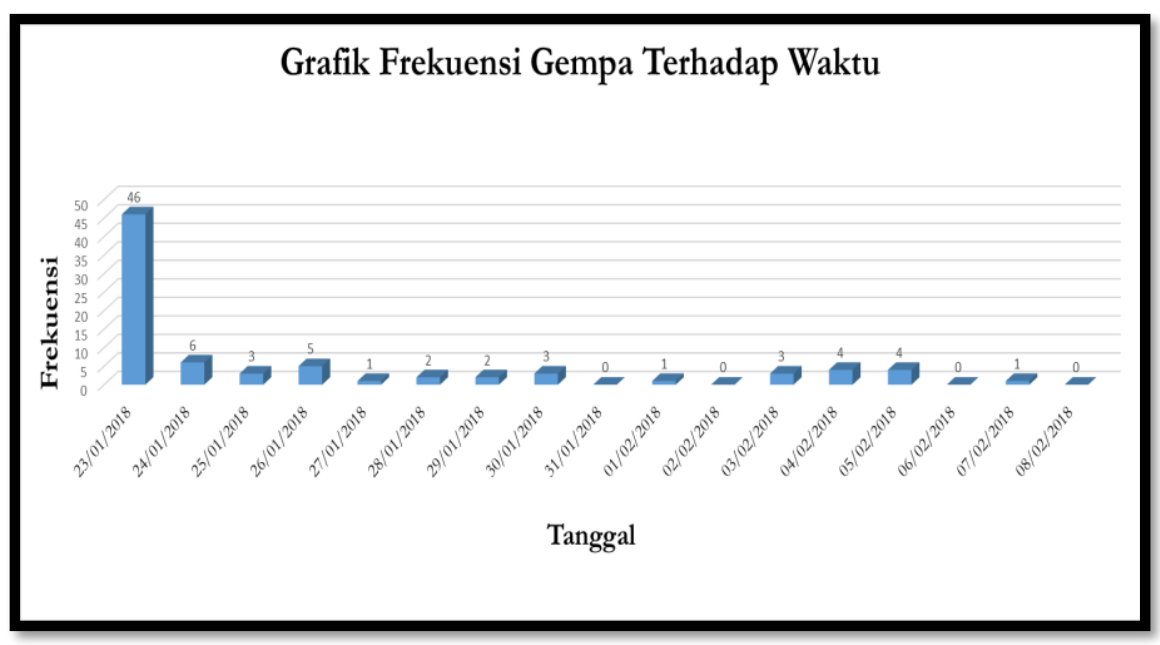

GAMBAR 5.Grafik frekuensi kumulatif gempa bumi

Berikut ini ditampilkan tabel hasil perhitungan gempa susulan di Banten 23 Januari 2018 :

TABEL 1. Hasil perhitungan peluruhan gempa bumi Banten masing-masing metode

\begin{tabular}{ccccc}
\hline Metode & $\mathbf{a}$ & $\mathbf{b}$ & $\mathbf{P}$ & $\mathbf{t}$ (hari) \\
\hline Omori & 18.3698473607 & 1.7653458706 & 0.0877253197 & 16 \\
\hline Mogi \& Utsu I & 1.3274578528 & -0.0544370337 & -0.4006583468 & 5 \\
\hline Mogi \& Utsu II & 1.3490302943 & -0.2914058290 & -0.4382701673 & 2 \\
\hline
\end{tabular}

Jika dibuat grafik, garis menunjukkan bahwa semakin bertambahnya hari maka frekuensi gempa susulan yang terjadi semakin menurun.

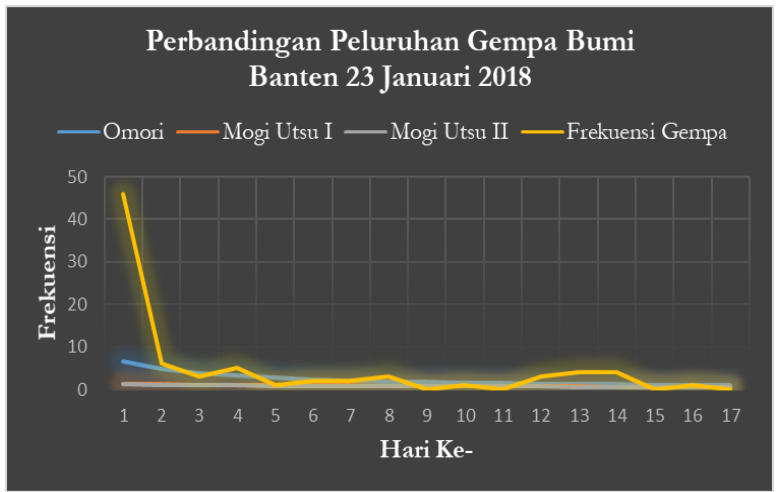

(a)

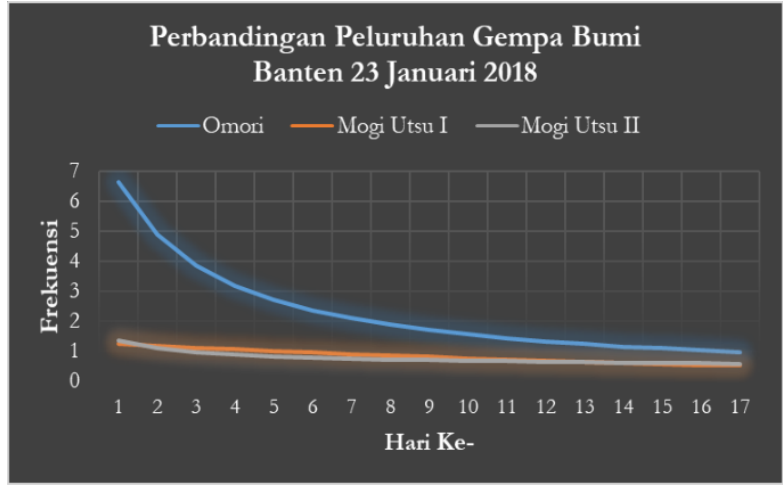

(b)

GAMBAR 6. Grafik perbandingan peluruhan gempa bumi Banten 23 Januari 2018 (a) terhadap ketiga metode dan frekuensi gempa sebenarnya (b) terhadap ketiga metode

Metode Omori menghasilkan perhitungan bahwa pada hari ke-16 gempa susulan di Banten akan berakhir. Metode Mogi \& Utsu I mendapatkan hasil perhitungan bahwa pada hari ke-5 gempa susulan di Banten akan berakhir, namun metode ini dianggap kurang menggambarkan peluruhan gempa bumi di Banten karena Metode Mogi \& Utsu I digunakan untuk kasus gempa dengan $\mathrm{t}>100$. Metode Mogi 
\& Utsu II memperoleh hasil yang sangat singkat yaitu waktu berakhirnya gempa susulan berakhir pada hari ke-2, namun metode ini juga dianggap kurang tepat dalam menggambarkan aktivitas aftershock di Banten karena dalam kurun waktu tersebut gempa susulan masih terus terjadi.

Beberapa penelitian menjelaskan bahwa metode yang paling tepat untuk digunakan dalam mendeskripsikan aktivitas gempa susulan yang terjadi di Pulau Jawa, Sumatera dan Sulawesi adalah Metode Omori. Hal ini dikarenakan hasil yang didapat melalui perhitungan mendekati hasil rill di lapangan. Menurut Rohmawati Tita(2018), berdasarkan hasil pengolahan data dan analisis bahwa untuk memperkirakan waktu berakhirnya gempabumi susulan disetiap wilayah berbeda-beda, wilayah Sumatera lebih cocok dengan menggunakan metode Omori karena hasilnya mendekati hasil riil dilapangan, untuk wilayah Jawa cocok menggunakan metode Omori, wilayah Papua menggunakan metode Mogi II, wilayah Sulawesi cocok menggunakan metode Omori, wilayah Maluku menggunakan metode Utsu, sedangkan metode yang tepat untuk wilayah Kalimantan adalah metode Mogi II.

\section{SIMPULAN}

Berdasarkan penelitian yang telah dilakukan, dapat disimpulkan bahwa metode yang paling tepat untuk mengetahui waktu berakhirnya gempa susulan di Banten tanggal 23 Januari 2018 adalah Metode Omori dengan waktu berakhirnya gempa bumi pada hari ke-16 untuk $n(t)=1$ dan koefisien korelasinya sebesar 0.087 .

\section{UCAPAN TERIMA KASIH}

Penulis mengucapkan terima kasih kepada semua pihak yang telah membantu dalam menyelesaikan penelitian ini.

\section{REFERENSI}

[1] Tim Pemuktakhiran Peta Bahaya Gempa Indonesia Tahun 2007 dan Penyiapan Pusat Studi Gempa Nasional, Peta Sumber dan Bahaya Gempa Indonesia Tahun 2017, Bandung: Pusat Litbang Perumahan dan Pemukiman, 2017.

[2] I P. Pudja, Fisika Batuan, Jakarta: PT.Nagakusuma Media Kreatif, 2015.

[3] T. Rohmawati, Analisis Waktu Berakhirnya Gempa Bumi Susulan dengan Menggunakan Metode Omori, Mogi I, Mogi II, dan Utsu untuk Kejadian Gempa Bumi di Indonesia Tahun 2009-2017, Bandung: UIN Sunan Gunung Djati, 2018.

[4] R. Efendi, Analisi Waktu Berakhirnya Gempa Bumi Susulan dengan Metode Mogi (Studi Kasus Gempa Bumi Pagai Selatan 25 Oktober 2010 dan Pariaman 30 September 2009), Jakarta: UIN Syarif Hidayatullah, 2011.

[5] C. DeMets, R. G. Gordon, D. F. Argus, and S. Stein, "Effect of Recent Revisions to The Geomagnetic Reversal Time Scale on Estimates of Current Plate Motions," in Geophysical Research Letters, 21(20), 1994, pp. 2191-2194. 
